Review

\title{
BAFF, APRIL and their receptors: Structure, function and signaling
}

\author{
Claudia Bossen, Pascal Schneider* \\ Biochemistry Department, University of Lausanne, Boveresses 155, CH-1066 Epalinges, Switzerland
}

\begin{abstract}
BAFF, APRIL and their receptors play important immunological roles, especially in the B cell arm of the immune system. A number of splice isoforms have been described for both ligands and receptors in this subfamily, some of which are conserved between mouse and human, while others are species-specific. Structural and mutational analyses have revealed key determinants of receptor-ligand specificity. BAFF-R has a strong selectivity for BAFF; BCMA has a higher affinity for APRIL than for BAFF, while TACI binds both ligands equally well. The molecular signaling events downstream of BAFF-R, BCMA and TACI are still incompletely characterized. Survival appears to be mediated by upregulation of Bcl-2

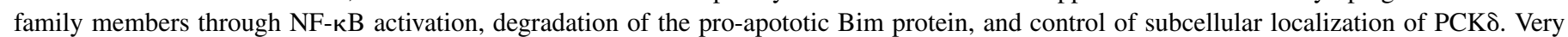
little is known about other signaling events associated with receptor engagement by BAFF and APRIL that lead for example to B cell activation or to CD40L-independent Ig switch.
\end{abstract}

(C) 2006 Elsevier Ltd. All rights reserved.

Keywords: B cells; Signaling; Structure; BAFF; Splice variants

\section{Introduction}

The TNF family ligands APRIL (CD256, TNFSF13) [1] and BAFF (also known as BLyS, TALL-1, CD257 and TNFSF13B) [2-4] interact with three TNFR family members, TACI (CD267, TNFRSF13B) [5], BAFF-R (also known as BR3, CD268 or TNFRSF17) [6,7] and BCMA (CD269, TNFRSF13C) [8]. APRIL and TACI also bind independently to glycosaminoglycan structures such as those present in syndecan-1 (CD138), or other proteoglycans [9-11].

The interaction pattern between BAFF, APRIL and their receptors is both specific and redundant: BAFF-R binds to BAFF, BCMA binds to APRIL, and TACI binds to BAFF and APRIL. In addition, BCMA binds BAFF with weaker affinity. Despite this complexity, the function of individual members of this subfamily in the immune system is relatively well understood, in great part as a result of the generation of a panel of mouse mutants. Recent papers have reviewed these functions, e.g. [12-14]. The present review seeks to provide insight into three aspects of BAFF biol-

Abbreviations: APRIL, a proliferation-inducing ligand; BAFF, B cell activating factor of the TNF family; BAFF-R, BAFF receptor; BCMA, B cell maturation antigen; TACI, transmembrane activator and CAML interactor; TRAF, TNF receptor-associated factor; TWEAK, TNF homologue with weak apoptosisinducing activity

* Corresponding author. Tel.: +41 21692 5709; fax: +41 216925705 .

E-mail address: pascal.schneider@unil.ch (P. Schneider). ogy: description of the numerous splice variants described for the different members of the BAFF complex; binding specificities of BAFF-R, BCMA and TACI and the structural determinants underlying ligand selectivity; and a summary overview of the fragmentary information available concerning the signaling pathways engaged by BAFF and APRIL, in the context of their known functions.

\subsection{Splice variants of APRIL, BAFF and their receptors}

\subsection{1. $B A F F$}

The TNF family ligand BAFF is a Type II membrane-bound protein, which can be released as a soluble trimeric ligand upon proteolytic processing at a furin consensus site. In the human BAFF gene, exon 1 codes for the transmembrane domain and its flanking regions, exon 2 for the furin processing site, and exons 3-6 for the TNF homology domain (THD), which binds to receptors (Figs. 1A and 2A).

At neutral or basic $\mathrm{pH}, 20$ trimers of soluble recombinant human BAFF associate into a 60 -mer virus-like structure, which irreversibly dissociates into trimers at acidic $\mathrm{pH}$, or when fused to N-terminal extensions such as a myc tag [15,16] (Fig. 3C). This association is dependent on an extended loop, known as the "Flap", that is unique to BAFF in the TNF family [15] (Fig. 3A and B). The physiological importance of the BAFF 60-mer is unclear, but it is a biologically active entity that can bind receptors and is moderately more active than trimers in the 


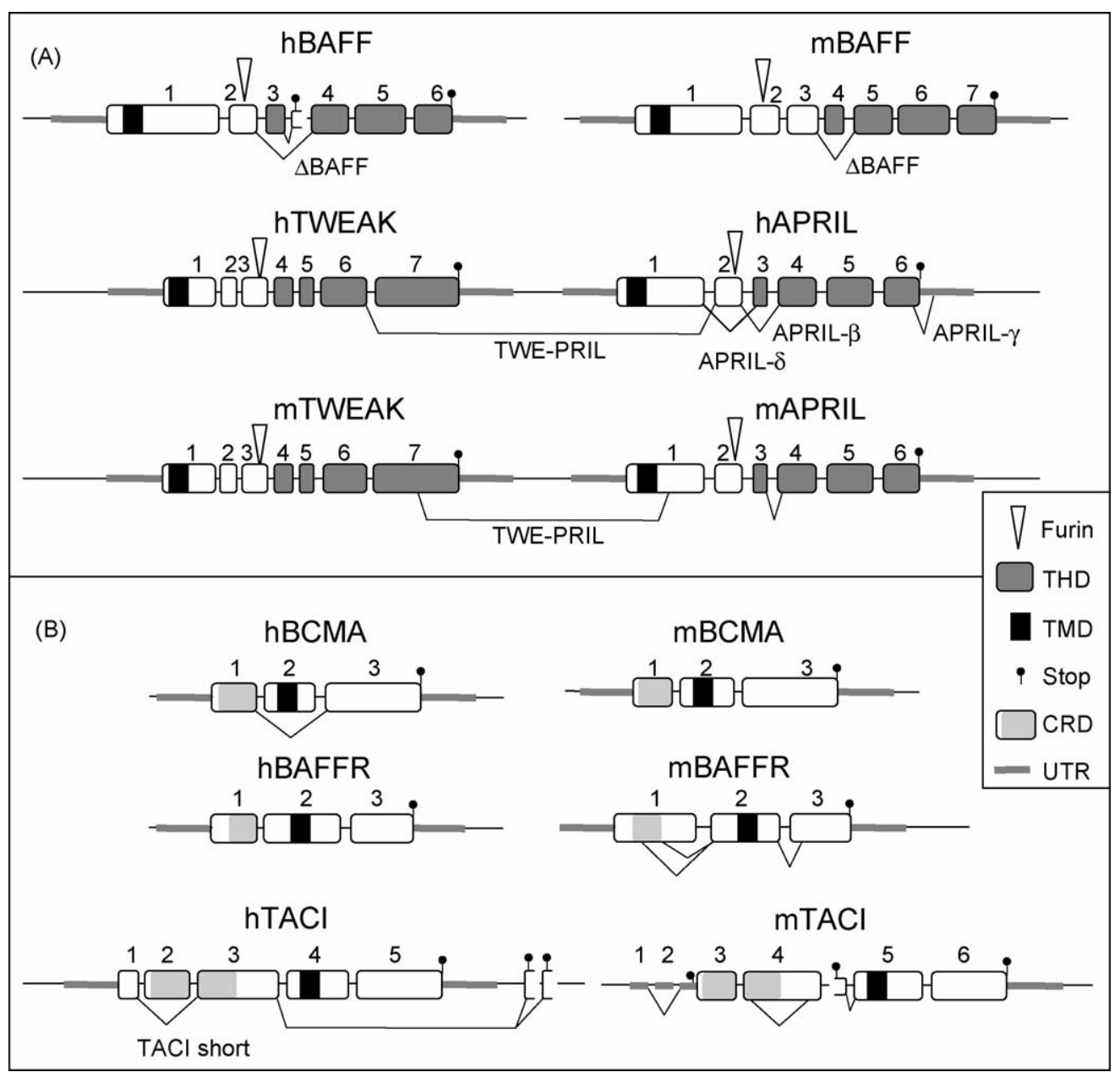

Fig. 1. Genomic organization of BAFF, APRIL and their receptors. (A) BAFF and APRIL. (B) BAFF-R, BCMA and TACI. Exons are represented as boxes and are shown to scale. The size of introns (thin line) and untranslated portions of the exons (UTR, thick lines) are not shown to scale. Alternative splicing events are shown, and the name of the resulting protein is sometimes indicated. Alternative splice isoforms were detected by screening the NCBI database for non-redundant and EST sequences. Furin: sequence coding for a consensus furin processing site (R-X-R/K-R). THD: TNF homology domain. TMD: transmembrane domain. Stop: stop codon. CRD: cysteine-rich domain (ligand-binding domain). UTR: $5^{\prime}$ and $3^{\prime}$ untranslated regions.

in vitro assays $[15,17]$. Endogenously produced 60 -mer BAFF has recently been detected in supernatants of an histiocytic cell line [17].

The gene for mouse BAFF contains an additional exon encoding a stretch of 30 amino acids located between the furin site and the THD (Fig. 1A). This extension is predicted to prevent 60-mer formation in the mouse, although this has not been formally demonstrated. In both species, alternative splice variants, in which exon 3 (exon 4 in the mouse) is skipped, generate an in-frame deletion of the first $\beta$-sheet of the THD to produce a splice variant called $\triangle \mathrm{BAFF}$ (Figs. 1A, 2 and $3 \mathrm{~A}$ ). The structural impact of this deletion is unknown, but does not seem to prevent surface expression and heteromerization of $\triangle \mathrm{BAFF}$ with BAFF, yet appears to prevent release of the soluble form [18]. Transgenic mice expressing $\triangle \mathrm{BAFF}$ in myeloid and dendritic cells display reduced B cell number and impaired T-dependent humoral responses, consistent with $\triangle \mathrm{BAFF}$ being a dominantnegative inhibitor of BAFF [19]. The splicing event in mouse $\triangle \mathrm{BAFF}$ creates a functional N-linked glycosylation site [18], which is interesting in view of the fact that gain of glycosylation can considerably affect the biological activity of extracellular proteins [20].

Failure to splice intron 1 in human BAFF [18], or alternative splicing to an acceptor site in intron 3 are relatively frequent events, but result in the production of no or prematurely terminated BAFF protein (Figs. 1A and 2A).

\subsubsection{APRIL}

The architecture of the APRIL gene resembles that of BAFF (Fig. 1). However, APRIL does not form 60-mers, but possesses residues close to the furin processing site in exon 3 that are crucial for binding to glycosaminoglycans (Fig. 2). APRIL binds sulfated glycosaminoglycans at sites independent from those used to bind other receptors $[9,10]$. The relevance of this binding is unclear, but may serve to accumulate and/or multimerize APRIL in the extracellular matrix or at the surface of syndecan-positive cells. It thus may facilitate access to its receptor TACI, which also interacts with syndecans [11], or to intracellular BCMA [21] upon syndecan internalization. 


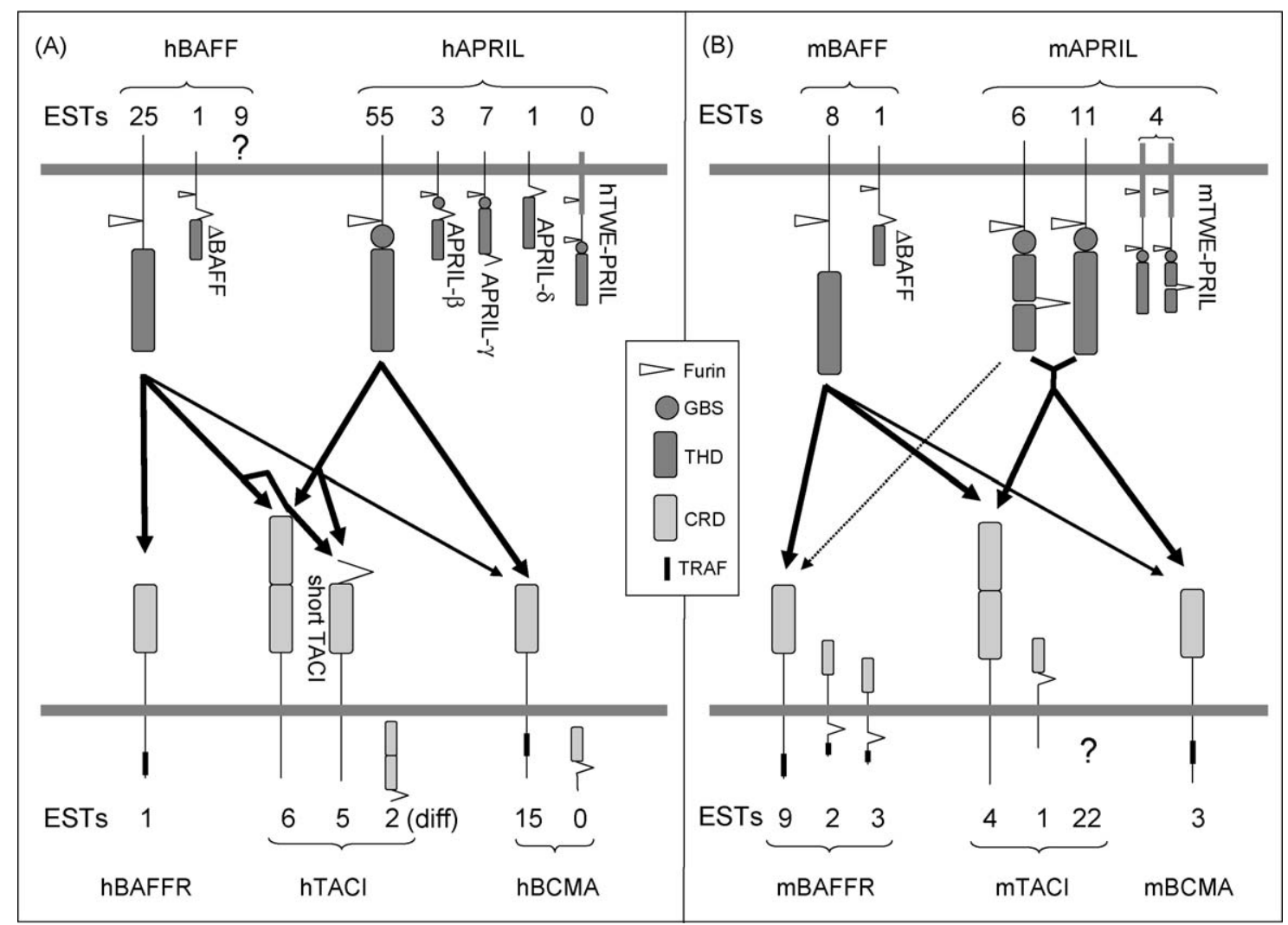

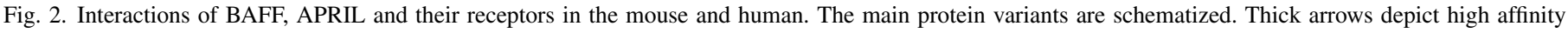

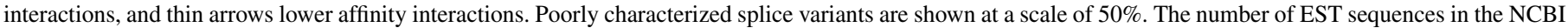

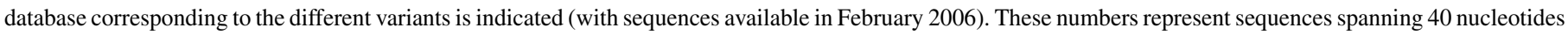

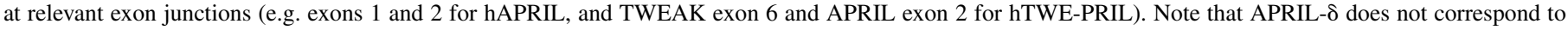

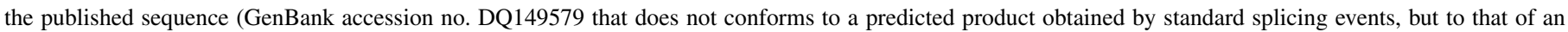

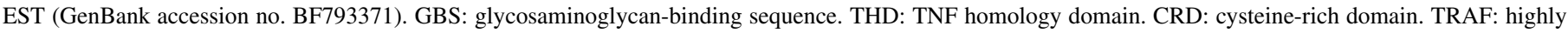
conserved region in BAFF-R and BCMA that binds to TRAF3.

A rare splicing event combines exon 1 of human APRIL to an alternative acceptor site in exon 3, thus generating a predicted membrane-bound, uncleavable human APRIL with no binding to glycosaminoglycans (APRIL- $\delta$ ) (Figs. 1A and 2A). Omission of exon 3 yields APRIL- $\beta$, an homologue of $\triangle$ BAFF that also lacks the first $\beta$-sheet of the THD [22], and by analogy with $\triangle$ BAFF may regulate APRIL activity in a dominant-negative manner [18] (Figs. 1A, 2A and 4A). APRIL- $\gamma$ is generated by splicing of a cryptic intron in exon 6 , resulting in a four amino acids C-terminal truncation that is replaced by a single residue, but this isoform has not been further studied [22] (Figs. 1A, 2A and 4A). No similar sequences have been reported or detected in ESTs of murine APRIL. Mouse APRIL does, however, exist as two variants differing by a single amino acid (Ala120) which are found at similar frequencies. This subtle sequence difference originates from alternative use of two splice acceptor sites only three nucleotides apart at the beginning of exon 4. A similar splicing event was previously reported in another TNF family member, EDA, whose variants differ by two amino acid residues only, yet display distinct receptor specificities [23]. In the case of mouse APRIL, both variants bind TACI and BCMA, and the only difference in receptor specificity was observed in the weak, but detectable, binding of the shorter APRIL variant to mouse BAFF-R (unpublished data) (Fig. 2B). This weak binding is, however, only observed in the mouse system and is unlikely to be physiologically relevant.

In both human and mouse genomes, the APRIL gene is located immediately $3^{\prime}$ of TWEAK, another TNF family ligand. An intergenic splicing event between exon 6 of TWEAK and exon 2 of APRIL generates human TWE-PRIL (Fig. 1A). Although this mRNA has been convincingly shown to exist at abundances close to that of APRIL in T cells and various cell lines [24], it is intriguing that there is currently no EST sequence in the NCBI database harboring this junction, whereas ESTs coding for regular APRIL (in the corresponding region) are abundant (Fig. 2A). However, mouse TWE-PRIL ESTs are present as two variants, with or without Ala120 (Fig. 2B). The genesis of mouse TWE-PRIL is very different from that of its human orthologue, as it uses unique splice sites within exon 7 of TWEAK and within exon 1 of APRIL (Fig. 1A). Despite this difference, both human and mouse TWE-PRIL contain the entire THD of APRIL, and are therefore expected to display the same receptor specificity as APRIL. Although TWE-PRIL has two furin consensus cleavage sites, the overexpressed form of human TWE-PRIL was resistant to cleavage, as was $\triangle \mathrm{BAFF}$ $[18,24]$. 


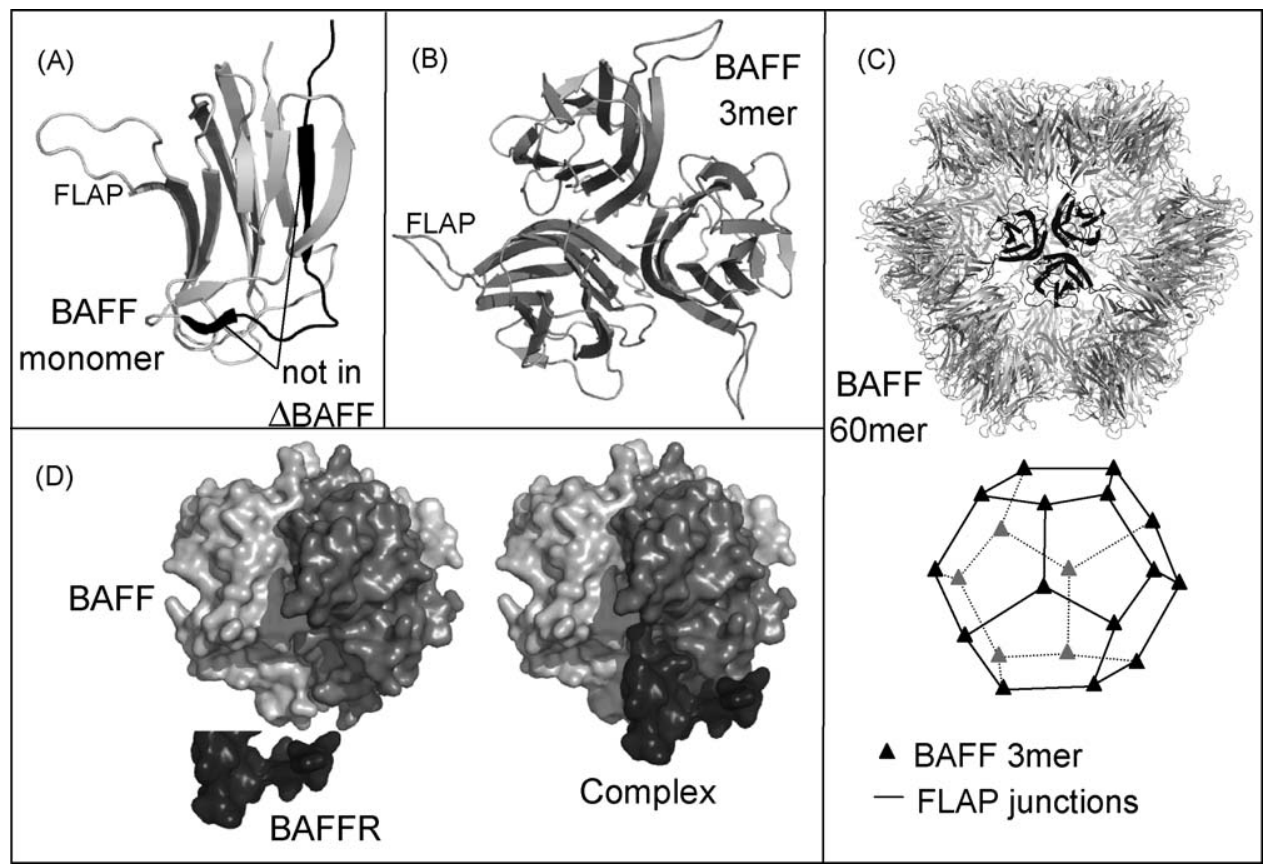

Fig. 3. Structure of BAFF. (A) BAFF monomer in the ribbon representation. The sequence encoded by exon 2 (missing in $\triangle \mathrm{BAFF}$ ) is shown in black. FLAP: D-E loop implicated in 60-mer formation. (B) BAFF trimer. (C) BAFF 60-mer, with one trimer highlighted in black at the center of the structure. The arrangement of the $20 \mathrm{BAFF}$ trimers in the dodecahedral structure is schematized below the actual structure. (D) BAFF trimer and BAFF-R monomer in surface representation, before and after binding. One BAFF trimer can bind three receptors, each contacting a single monomer within the BAFF trimer. Models were drawn with PyMol, based on coordinates files $1 \mathrm{OQE}$ and $1 \mathrm{OTZ}[31,32]$.

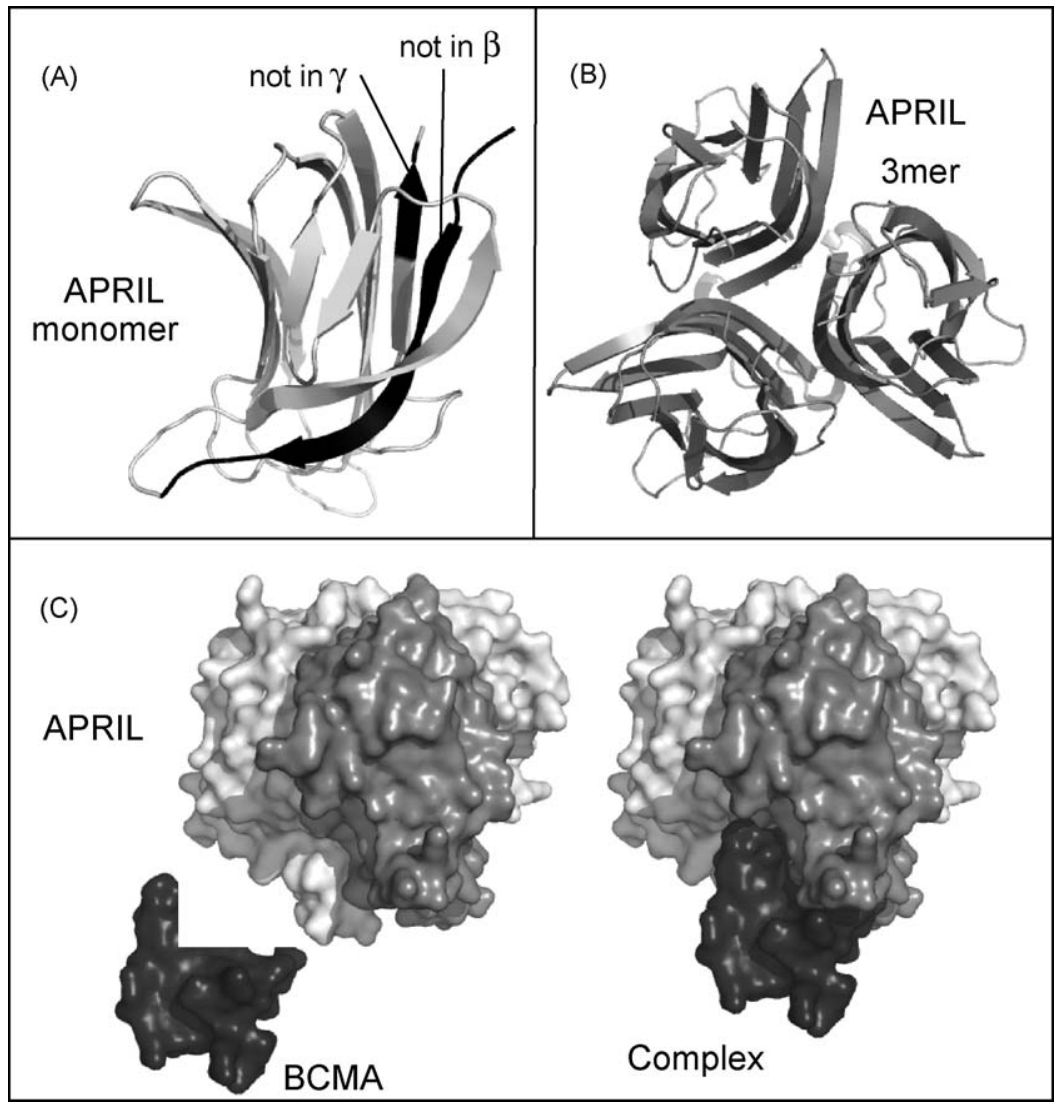

Fig. 4. Structure of APRIL. (A) APRIL monomer in ribbon representation. The sequences deleted in APRIL- $\beta$ and $-\gamma$ variants are shown in black. (B) APRIL trimer. (C) APRIL trimer and BCMA monomer in surface representation, before and after binding. An APRIL trimer can bind three receptors, each contacting a single monomer within the APRIL trimer. Structures were drawn based on the atomic coordinate file 1XU2 [29].

Please cite this article as: Claudia Bossen, Pascal Schneider, BAFF, APRIL and their receptors: Structure, function and signaling, Seminars in Immunology (2006), doi:10.1016/j.smim.2006.04.006. 


\subsubsection{BAFF-R and BCMA}

BAFF-R and BCMA (and TACI) lack a signal peptide and are therefore classified as Type III membrane proteins. Exon 1 encodes the ligand-binding domain (also called cysteine-rich domain or CRD), exon 2 the transmembrane domain and flanking regions, and exon 3 the intracellular domain (Fig. 1B). The intracellular domains of both BAFF-R and BCMA are strongly homologous over a short sequence of 18 amino acids, which in the case of BCMA contains a TRAF-binding consensus site (P/S/A/T-X-Q/E-E) (Fig. 2). BCMA is indeed known to bind several TRAFs [25,26]. Although the TRAF signature is not conserved in BAFF-R, this region binds to TRAF3 with high selectivity $[27,28]$. In the mutant A/WySnJ mouse, a $4.7 \mathrm{~kb}$ gene insertion event disrupts the $3^{\prime}$ end of the BAFF$\mathrm{R}$ gene, including part of this conserved sequence, leading to defective BAFF-R signaling [7]. The use of alternative splice donor and acceptor sites in exons 1 and 3, respectively, give rise to different mouse BAFF-R isoforms. These insertions and deletions occur outside the ligand and TRAF3 binding sites (Figs. 1B and 2B). Omission of exon 2 in human BCMA generates a predicted soluble receptor, but in the absence of a signal peptide, this protein is not expected to be secreted (Fig. 2A).

\subsubsection{TACI}

The $3^{\prime}$ genomic organization of TACI is similar to that of BCMA and BAFF-R, but the ligand-binding region is duplicated in an extra $5^{\prime}$ exon. This first ligand-binding domain has a much weaker affinity for BAFF and APRIL than the second one [29]. In human TACI only, an additional 5' exon encodes a short $\mathrm{N}$-terminal sequence. This often permits skipping of exon 2 to produce a short form of TACI lacking the first ligand-binding domain. This short TACI binds BAFF and APRIL as efficiently as the long form [29] (Figs. 1B and 2A). Human TACI is also subject to rarer intergenic splicing events removing the transmembrane and intracellular domains to yield soluble forms of TACI. However, TACI being a Type III protein, these proteins are not predicted to be secreted (Fig. 2A).

In mouse TACI, the initiating methionine and CRD1 are in the same exon. Excision of CRD1 is not possible in mouse TACI as it is in the human protein, because the $5^{\prime}$ non-coding exons do not contain an ATG codon in frame with the exon containing CRD2 (Fig. 1B). However, one sequence of TACI indicates that the reverse event can take place, i.e. deletion of the second CRD after splicing of a cryptic intron within exon 3 (Figs. 1B and 2B). Curiously, most mouse TACI transcripts start from within intron 4 and continue with exons encoding the transmembrane and intracellular portions of TACI. However, these transcripts lack initiating methionines and therefore should not encode proteins (Figs. 1B and 2B). It is not known if these transcripts regulate TACI expression or fulfill other specific functions. A practical outcome is that studies aimed at evaluating murine TACI expression at the RNA level will be influenced by the choice of RT-PCR primers.

In conclusion, conserved splicing events are relatively few ( $\triangle \mathrm{BAFF}$ and to a certain extent TWE-PRIL). Most other splicing events are species-specific, and therefore unlikely to play major biological roles.

\subsection{Specificity of BAFF and APRIL interactions}

Determining the true affinities of BAFF and APRIL for their receptors is not trivial. Indeed, measures performed with dimeric receptor-Ig proteins are subject to significant but unpredictable avidity effects that increase the apparent affinity. The avidity component is however removed by use of monomeric receptors, and results of such experiments are shown in Table 1. The consensus is that, on the one hand, BAFF binds to BAFF-R and

Table 1

Binding affinities of BAFF and APRIL for BAFF-R, BCMA and TACI

\begin{tabular}{|c|c|c|c|c|c|}
\hline Receptor & Ligand & Assay & Affinity & $\mathrm{nM}$ & Reference \\
\hline BAFF-R, monomer & BAFF & Compet. ELISA & $\mathrm{IC}_{50}$ & 92 & [34] \\
\hline BAFF-R, monomer & BAFF & Compet. Biacore & $K_{\mathrm{D}}$ & 16 & [99] \\
\hline BAFF-R, monomer & BAFF 3-mer & Compet. Biacore & $K_{\mathrm{D}}$ & 15 & {$[17]$} \\
\hline BAFF-R, monomer & BAFF 60-mer & Compet. Biacore & $K_{\mathrm{D}}$ & 9 & {$[17]$} \\
\hline BCMA, monomer & BAFF & Compet. ELISA & $\mathrm{IC}_{50}$ & 8000 & {$[35]$} \\
\hline BCMA, monomer & BAFF & Compet. Biacore & $K_{\mathrm{D}}$ & Not detected & {$[35]$} \\
\hline BCMA, monomer & BAFF & Compet. Biacore & $K_{\mathrm{D}}$ & 1600 & [99] \\
\hline TACI, monomer & BAFF & Compet. Biacore & $\mathrm{IC}_{50}$ & 1 & [29] \\
\hline $\mathrm{TACI}_{\mathrm{S}}$, monomer & BAFF & Compet. Biacore & $\mathrm{IC}_{50}$ & 2 & [29] \\
\hline BAFF-R, monomer & APRIL & Compet. Biacore & $K_{\mathrm{D}}$ & Not detected & [99] \\
\hline BCMA, monomer & APRIL & Compet. Biacore & $K_{\mathrm{D}}$ & 16 & [99] \\
\hline BCMA, monomer & APRIL & Compet. ELISA & $\mathrm{IC}_{50}$ & 6 & {$[35]$} \\
\hline TACI, monomer & APRIL & Compet. Biacore & $\mathrm{IC}_{50}$ & 11 & [29] \\
\hline $\mathrm{TACI}_{\mathrm{S}}$, monomer & APRIL & Compet. Biacore & $\mathrm{IC}_{50}$ & 6 & [29] \\
\hline BAFF-R, dimer & BAFF & Compet. ELISA & $\mathrm{IC}_{50}$ & 7 & {$[35]$} \\
\hline BAFF-R, dimer & BAFF & Compet. Biacore & app. aff. & $<0.03$ & [99] \\
\hline BCMA, dimer & BAFF & Compet. Biacore & app. aff. & 5 & {$[35]$} \\
\hline BCMA, dimer & BAFF & Compet. Biacore & app. aff. & 0.6 & [99] \\
\hline BAFF-R, dimer & APRIL & Compet. ELISA & $\mathrm{IC}_{50}$ & Not detected & {$[35]$} \\
\hline BCMA, dimer & APRIL & Compet. Biacore & app. aff. & 0.2 & {$[35]$} \\
\hline
\end{tabular}

Compet.: competition; app. aff.: apparent affinity. 
TACI with affinities in the nanomolar range, yet displays two to three order of magnitude weaker binding to BCMA. On the other hand, APRIL binds TACI and BCMA with high affinity (nanomolar range), but not at all to BAFF-R. When receptors are dimerized as Ig fusion proteins, all receptors efficiently bind ligands in the low to subnanomolar range, with the exception of BAFF-R that does not bind to APRIL (Table 1, and reviewed in [30]). In comparison, APRIL binding to heparan sulfate proteoglycans is weak $(20-80 \mu \mathrm{M})$ [30]. Whether endogenous BAFF can signal through BCMA in vivo is not known, but will certainly depend on avidity effects. Clustering of membrane-bound BCMA, clustering of membrane-bound BAFF or occurrence of multimerized forms of soluble BAFF (60-mer), are potential factors that may affect the avidity of the BAFF-BCMA interaction in vivo.

The molecular determinants of BAFF and APRIL specificity for their receptors have been solved through a number of elegant structural and mutational studies. BCMA and BAFF-R differ from other TNF receptor family members in that they possess a single cysteine-rich domain (CRD), which is used to establish extensive contacts with a single ligand monomer within BAFF or APRIL trimers [29,31,32] (Figs. 3D and 4C). Although TACI contains two CRDs, only the second one is necessary and sufficient for high affinity binding to BAFF and APRIL, so that the mode of TACI interaction with APRIL and BAFF is essentially the same as that of BCMA or BAFF-R [29]. This is in sharp contrast to other family members that contain up to four CRDs, and establish two main contact areas at the interface between two ligand protomers (reviewed in [33]).

BCMA, TACI and BAFF-R show perfect structural conservation in a $\beta$-hairpin structure that fits in a binding pocket of BAFF and APRIL and constitutes the conserved core of the interaction (Fig. 5). The hairpin structure is followed by a helix-loop-helix motive that is strikingly different among receptors: its spatial orientation differs in BCMA and TACI, independently of receptor binding, and BAFF-R contains only the first helix (Fig. 5). In a first approximation, it can be said that the hairpin is crucial for ligand binding, and that the $\mathrm{C}$-terminal domain defines ligand specificity. Systematic mutagenesis studies of the ligandbinding sequence of BAFF-R [34], BCMA [35] and TACI [29] led to the precise identification of residues dictating the ligand specificity. For example, an aromatic residue in the hairpin, present in BCMA and TACI, but not BAFF-R, is absolutely required for APRIL binding, but dispensable for BAFF binding (Fig. 5, F78/Y13/C24). Introduction of this hydrophobic residue in BAFF-R confers binding to APRIL [31]. BAFF-R contains an hydrophobic residue (Leu38) that favors binding to BAFF but is detrimental for APRIL, further explaining the exquisite specificity of BAFF-R for BAFF and not APRIL (Fig. 5, P95/R27/L38). The corresponding position in BCMA is occupied by an arginine, which has the reverse effect, i.e. favoring APRIL binding, but inhibiting the interaction with BAFF. BCMA also lacks an arginine in the hairpin that establishes specific contacts with BAFF but not APRIL, accounting for the weak affinity of BAFF for BCMA (Fig. 5, R84/H19/R30). Human BCMA contains an hydrophobic residue (Ile22) that favors BAFF binding, but is not required for APRIL binding (Fig. 5, I87/I22/V33). Interestingly, mutation of this residue to an arginine abrogates the BCMA-BAFF interaction without significantly affecting binding to APRIL [35]. Finally, TACI does not present residues which are detrimental for APRIL or BAFF binding, explaining its dual specificity [29]. However, the set of residues involved in BAFF or APRIL interaction with TACI is partially different (Fig. 5).

In conclusion, the complex binding specificities of the BAFF and APRIL ligands (Fig. 2) is now very well understood at the molecular level.

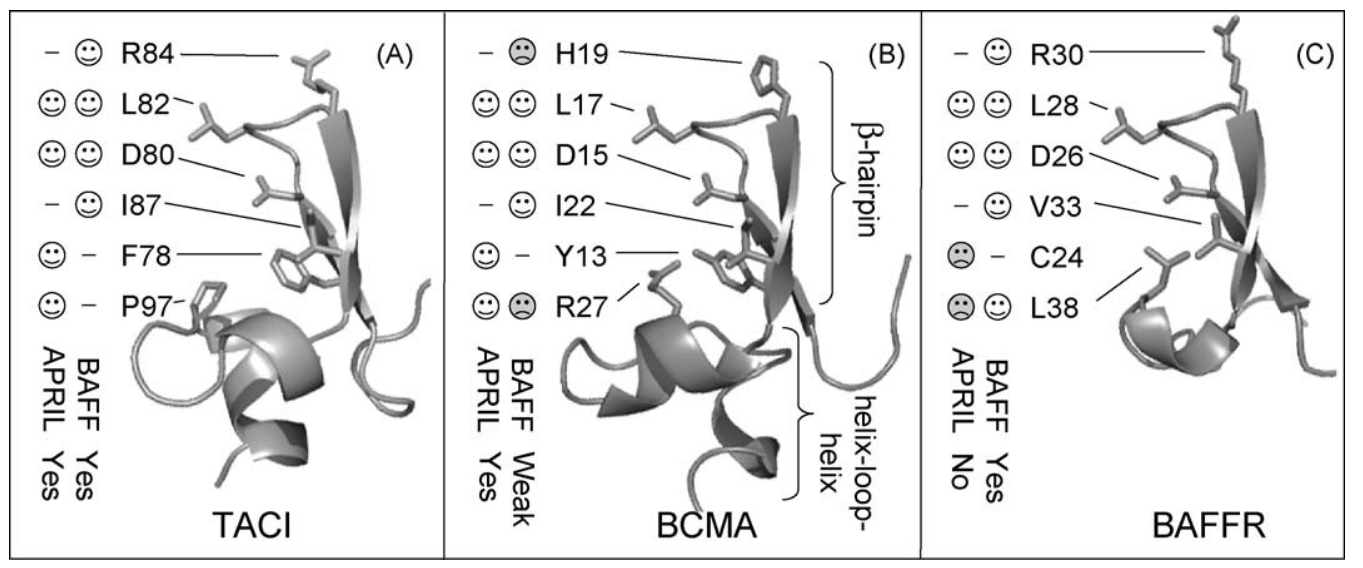

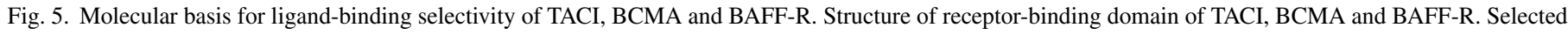

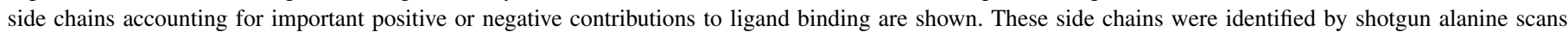

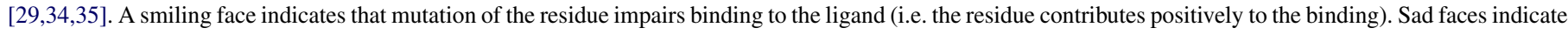

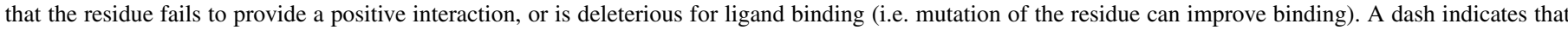

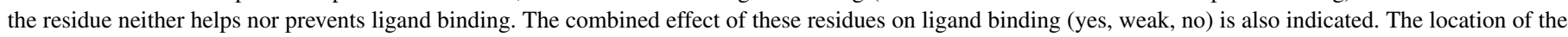

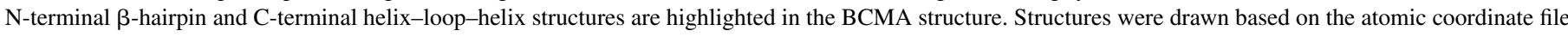
1OQD, 1OQE and 1XU1 [29,31]. 


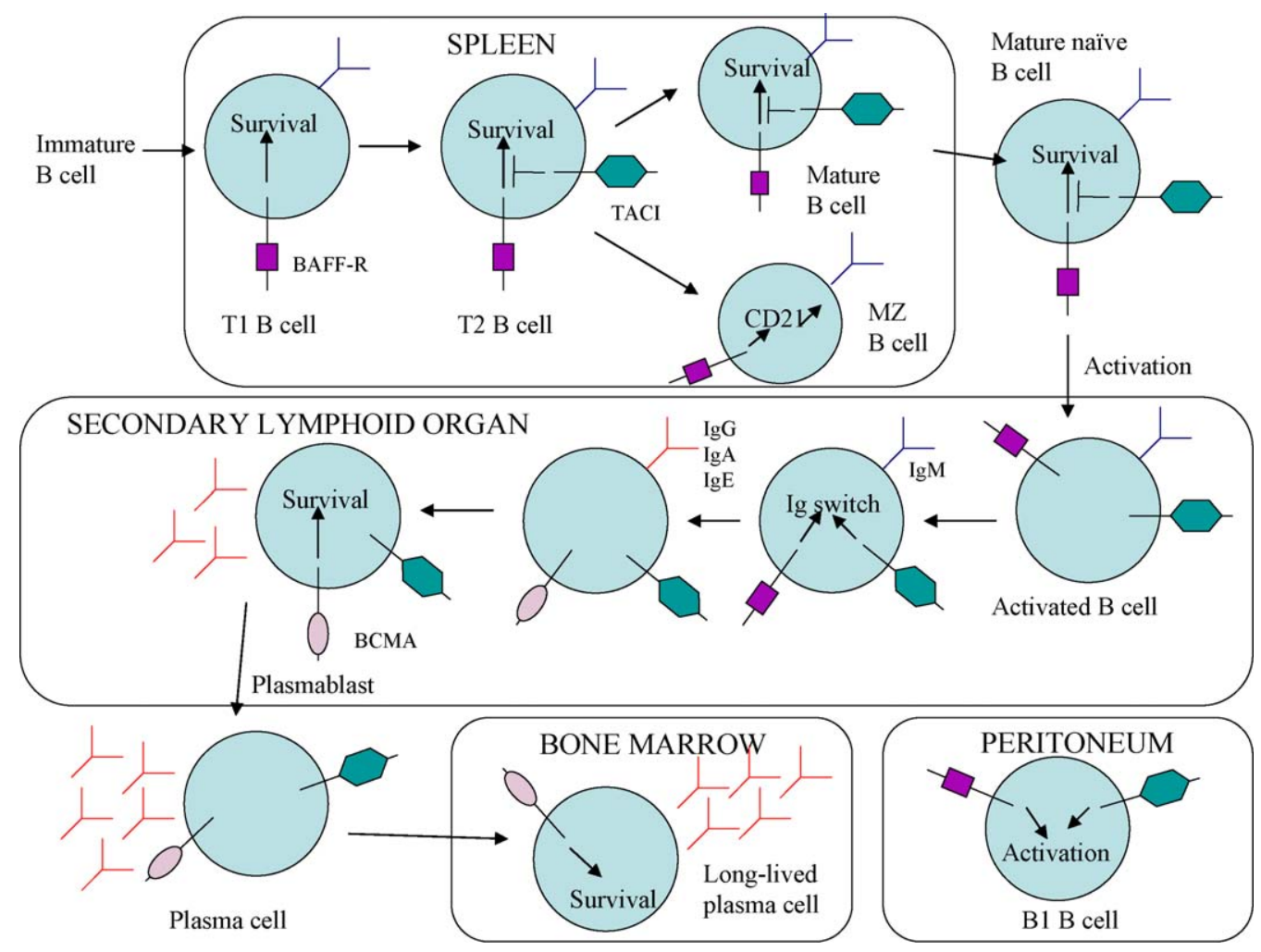

Fig. 6. Potential functions of APRIL and BAFF receptors in B cells. During development, B cells become dependent on signaling through BAFF at the transitional T1 stage. BAFF-R mediates a survival signal, whereas TACI acts as a negative regulator. BAFF-R is required for the formation of marginal zone B cells and upregulation of CD21. During terminal differentiation, B cells become dependent on BCMA for survival. The dependence on the respective receptors correlates with increased expression. Furthermore, in the context of T cell-independent responses, BAFF-R and TACI are likely important mediators of antibody class switching as these receptors are able to mediate class switches to IgE and IgG and, for TACI, to IgA. TACI and BAFF-R are also expressed on B-1 B cells and may play a role in their activation.

\section{Biological functions of receptors and signaling pathways}

\subsection{BAFF-R and BCMA are involved in B cell survival}

B cells enter the spleen at an immature T1 stage and further differentiate through the immature $\mathrm{T} 2$ stage to either mature or marginal zone B cells (Fig. 6). During differentiation, the requirement for a functional $\mathrm{B}$ cell receptor $(\mathrm{BCR})$ is highlighted in $\operatorname{Ig} \beta \Delta C$ mice [36]. The BCR consists of a surface immunoglobulin, which has no signaling capacity, and of $\operatorname{Ig} \beta$ and $\operatorname{Ig} \alpha$ chains that signal through their cytoplasmic tails. Deletion of the cytoplasmic tail of $\operatorname{Ig} \beta(\operatorname{Ig} \beta \Delta C)$ abrogates development of B cells beyond the immature stage. In addition to the BCR signal, a survival signal provided by BAFF is required during differentiation, and BAFF deletion results in greater than $90 \%$ loss of mature B cells $[37,38]$. This loss results from reduced survival at all stages beyond the immature T1 stage [39]. Initially, a maturation block at the T1 stage was reported in $\mathrm{BAFF}^{-1-}$ mice [37], but these conclusions were skewed as they relied on two markers, CD21 and CD23, whose expression is regulated by BAFF [39]. Overexpression of the anti-apoptotic proteins $\mathrm{Bcl}-2$ or $\mathrm{Bcl}-\mathrm{x}_{\mathrm{L}}$ in $\mathrm{B}$ cells of mice with deficient BAFF function significantly rescues $B$ cell number, maturation and function, in line with a survival function for BAFF [40,41].
However, the partial rescue suggests that BAFF fulfills other, non-survival functions. The receptor crucial for mediating BAFF survival signals at this stage is BAFF-R, as shown by loss of mature $\mathrm{B}$ cells in BAFF-R mutant $\mathrm{A} / \mathrm{WySnJ}$ mice $[6,7]$. The results were confirmed by deletion of BAFF-R $[42,43]$. At this stage of $\mathrm{B}$ cell maturation, TACI acts as a negative regulator, because $\mathrm{TACI}^{-1-}$ mice have a two to three-fold increased number of mature B cells [43-46]. BCMA is not implicated in survival of $\mathrm{B}$ cells at this stage of differentiation as $\mathrm{BCMA}^{-1-}$ mice have unaltered $\mathrm{B}$ cell numbers [37,47]. However, BCMA is an important player at later stages of B cell differentiation and has been shown to be important for the survival of longlived bone marrow plasma cells [48] and likely for the survival of plasmablasts [49]. This correlates with upregulated BCMA expression during terminal $\mathrm{B}$ cell differentiation [50]. As BCMA binds APRIL with high affinity, the APRIL-BCMA axis might predominate at later stages of $\mathrm{B}$ cell differentiation, or at least partially replace the dependence for BAFF.

\subsection{Survival as a result of $N F-\kappa B$ activation}

Different aspects of the signaling downstream of BAFF-R, which leads to B cell survival, are beginning to be understood (Fig. 7). Activation of NF-кB often correlates with survival outcomes. Activation of dimeric NF- $\kappa$ B transcription factors in B 


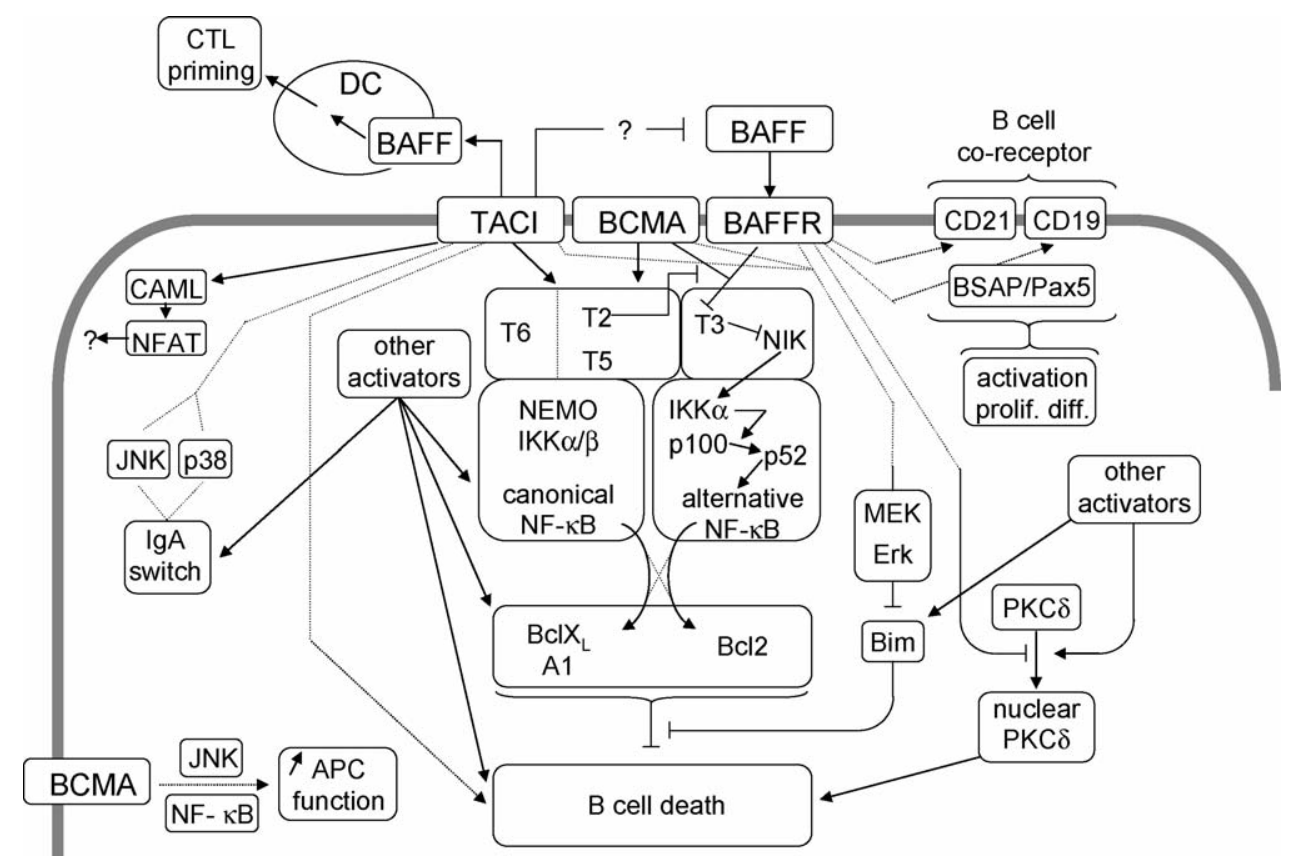

Fig. 7. Summary of signaling pathways downstream of BAFF receptors. The molecular events leading to survival, Ig switch or other responses downstream of BAFF-R, TACI and BCMA are in general poorly characterized. Dashed lines indicate undefined molecular links, whereas filled arrows indicated possible molecular links. For example, the inhibitory role of BAFF-R on TRAF3 remains speculative (see text for further details).

cells proceeds either through the canonical, NEMO-dependent pathway, or through the alternative, NEMO-independent pathway [51]. The canonical pathway requires the IKK complex, composed of the kinases IKK $\alpha$ and IKK $\beta$, and of the essential modulator NEMO. It can be activated by several proteins including TRAF2, 5 and 6 [52], and yields NF-кB dimers containing the p50 subunit. The alternative pathway can be activated by receptors linked to the kinase NIK and requires IKK $\alpha$ (but not IKK $\beta$ and NEMO). It is hallmarked by the inducible processing of the NF-кB2 p100 protein to the p52 fragment, a component of NF-кB dimers [51]. TRAF2 and 5, but not TRAF6, can also participate in the alternative pathway [53].

The importance of the alternative pathway downstream of BAFF-R has been demonstrated in vivo [54]. Mice deficient in p52 display a reduction in mature $B$ cells. Bone marrow-derived p52-deficient transitional T1 B cells respond only very weakly to BAFF. Similar results were obtained using cells from aly/aly mice, which harbor an inactivating mutation in the NIK kinase. The importance of IKK $\alpha$ for B cell maturation is demonstrated in vivo by $\mathrm{IKK} \alpha^{-/-}$bone marrow chimeras, which display a reduction in mature $B$ cells [55]. This reduction is however not as strong as that observed in $\mathrm{BAFF}^{-1-}$ mice. A penetrance of $\mathrm{B}$ cell depletion similar to that observed in BAFF or BAFF-Rdeficient mice is only observed in mice lacking components of both classical and alternative pathways, e.g. p52 and p50 [56]. There are two possible explanations: either p50 can compensate to some extent for $\mathrm{p} 52$ loss in the alternative pathway, or BAFF$\mathrm{R}$ activates both canonical and alternative pathways (Fig. 7). Phosphorylation of IкB $\alpha$, which could reflect activation of the canonical pathway, has been documented downstream of BAFF$\mathrm{R}$ in mature, but not immature, $\mathrm{B}$ cells $[57,58]$. However, this activation is weak compared to known activators of the classical NF-кB pathway.

The molecular link between BAFF-R and the activation of NF- $\mathrm{KB}$ is unclear. BAFF-R only binds to TRAF3, but to none of the NF- $\mathrm{BB}$-activating TRAFs [27]. Analysis of the TRAF3 binding portion of BAFF-R co-crystallized with TRAF3 revealed that $\mathrm{Gln}^{379}$ of TRAF3, which is not conserved in TRAF2, is important for this binding, providing a molecular basis for this specificity [28]. However, TRAF3 is not a positive regulator of BAFF-R-mediated survival signals, because $\mathrm{TRAF}^{-1-}$ fetal liver chimeras form B cells relatively normally [59]. In support of this negative role, TRAF3 is also known to inhibit alternative NF- $\mathrm{KB}$ activation by TRAF2 and 5 downstream of many TNF receptors [53]. An interesting concept was raised by Liao et al. who showed that TRAF3 inactivates NIK in the M12 B cell line, but that this inhibition is relieved by CD40 or BAFF-R signaling. In other words, BAFF-R would act as a repressor of TRAF3 [60]. This concept predicts both loss of B cell survival upon disruption of the TRAF3/BAFF-R interaction, and survival of B cells in the absence of TRAF3. However, BAFF-induced TRAF3 degradation was not confirmed in other cell types, and activation of the alternative pathway was observed in mature $\mathrm{B}$ cells following BAFF stimulation without (or with little) TRAF3 degradation [61]. It remains however possible that NIK may be stabilized by recruitment to BAFF-R, with or without TRAF3, and signal despite the presence of TRAF3. In this respect, NIK has been shown to be recruited to CD27, another TNF receptor family member [62].

Other TRAFs regulate the alternative NF-кB pathway. Mice with B cell-specific TRAF2 deletion revealed TRAF2 as a negative regulator of the alternative pathway [61]. Mature B cells 
accumulate in these mice and addition of BAFF cannot induce further generation of $\mathrm{p} 52$. As BAFF-R does not interact with TRAF2, it remains to be elucidated how TRAF2 inhibits the alternative NF- $\mathrm{B}$ pathway downstream of BAFF-R.

Act1, an adaptor protein without enzymatic activity, was first described as an NF- $\mathrm{BB}$ activator in the CD40 signaling pathway [58]. Generation of Act $1^{-/-}$mice demonstrated that Act1 actually functions as a negative regulator of both NF$\kappa \mathrm{B}$ pathways downstream of CD40 [63]. As these mice display an accumulation of $\mathrm{B}$ cells, and because a recruitment of Act1 to BAFF-R was observed, a negative role for Act1 downstream of BAFF-R was postulated. Nevertheless, immature T1 B cells accumulate along with other splenic B cell subsets, arguing against a specific role of Act1 downstream of BAFF-R.

The identity of the relevant NF- $\mathrm{B}$-regulated genes expressed in response to BAFF-R signaling remains unsettled. BAFF induces upregulation of anti-apoptotic Bcl-2 members such as Bcl- $\mathrm{x}_{\mathrm{L}}$ or Bcl-2, leading to survival $[54,57]$. Bcl- $\mathrm{x}_{\mathrm{L}}$ (but not Bcl2 ) is a well-documented target of the classical NF-кB pathway [64]. It is tempting to speculate that Bcl-2 might be a target of the alternative pathway induced by BAFF in B cells [65]. Indeed, $\mathrm{Bcl}-2$ levels are reduced in $\mathrm{p} 50^{-/-} \mathrm{p} 52^{-/-}$and $\mathrm{c}-\mathrm{Rel}^{-/-} \mathrm{RelA}^{-I-}$ double knock-out mice $[56,66]$ and the Bcl-2 promoter contains potential NF-кB-binding sites $[64,65,67]$. Nevertheless, upregulation of Bcl-2 after BAFF stimulation remains controversial [57,68]. Finally, the Bcl-2 family member A1 was also proposed as a target of BAFF signaling [69], but these results were challenged by data suggesting that A1 was a target of BCR signaling only [68].

\subsection{BAFF-R, TACI and $T$ cells}

In addition to its role in $\mathrm{B}$ cell survival, BAFF-R has also been implicated in T cell physiology. BAFF can costimulate proliferation of suboptimally stimulated T cells in a BAFF-R-dependent and TACI-independent manner [70,71]. The in vivo relevance was demonstrated by studying cardiac allograft rejection. After allograft transplantation, BAFF binding to BAFF-R in $\mathrm{CD}^{+} \mathrm{T}$ cells costimulated alloproliferation and contributed to allograft rejection [72]. Signaling in T cells has not been investigated to date, except for Bcl-2 upregulation in response to BAFF stimulation [71].

Although TACI was first described as being expressed in $\mathrm{T}$ cells [5], subsequent studies have shown that wild type murine $\mathrm{T}$ cells do not expresses more TACI than $\mathrm{TACI}^{-1-} \mathrm{T}$ cells [71]. If $\mathrm{T}$ cells express no TACI, how can it be that cytotoxic $\mathrm{T}$ lymphocyte (CTL) priming is severely compromised in $\mathrm{TACI}^{-/-}$ mice? [73]. B cells are required for CTL priming, but $\mathrm{TACI}^{-/-}$ $B$ cells cannot fulfill this function. Moreover, low amounts of TACI-Ig could circumvent the need for B cells in CTL priming in vivo, suggesting the following scenario: TACI on B cells binds to membrane-bound BAFF expressed on dendritic cells. Through a postulated reverse BAFF signaling, dendritic cells gain the ability to prime $\mathrm{CD}^{+} \mathrm{T}$ cells (Fig. 7) [73]. It will be interesting to see if direct evidence of reverse signaling through BAFF can be obtained.

\subsection{Activation of $N F-\kappa B$ by BCMA and TACI}

The signaling of BCMA leading specifically to plasmablast and/or plasma cell survival has not been investigated, but may involve similar signaling pathways as those induced by BAFF$\mathrm{R}$. In this regard, BCMA is a potent activator of the classical NF-кB pathway $[25,26,74]$, most probably through its ability to bind members of the TRAF family. Two reports have described BCMA interaction with TRAF1, 2 and 3, or with TRAF5 and 6, but not 2, respectively $[25,26]$.

In contrast to BCMA and BAFF-R, TACI is regarded as a negative regulator of $B$ cell survival [43-46], although it is a potent activator of the classical NF- $\mathrm{B}$ signaling pathway and can interact with TRAF2, 3, 5 and 6 [75]. In vitro studies have shown that TACI can induce apoptotic signals in response to agonistic antibody stimulation [46]. Regardless of intracellular signaling, TACI can also be cleaved [76] and might regulate B cell survival indirectly through BAFF sequestration.

\subsection{Survival as a result of pro-apoptotic protein degradation}

BH3-only proteins are pro-apoptotic members of the Bcl-2 family. This subgroup, which includes Bid, Bad, Bik, Bim, Bmf, Hrk, Noxa and Puma, induces apoptosis by counteracting antiapoptotic Bcl-2 family members. Bim is required for apoptosis and proper development of hematopoietic cells [77]. BCR stimulation in WEHI-231 mouse B cells and primary immature B cells results in increased levels of the pro-apoptotic factor Bim [78]. Craxton et al. recently discovered that stimulation through either BAFF-R, TACI or BCMA leads to decreased Bim protein levels [78]. Bim degradation requires MEK and Erk activation, as shown by using a specific MEK inhibitor. The molecular link between the receptors and Erk activation was not investigated. However, the relevance of Bim downstream of BAFF-R is supported by genetic evidence: $\mathrm{Bim}^{-/-}$mice display an accumulation of transitional $\mathrm{T} 2$ and mature $\mathrm{B}$ cells but transitional T1 B cells are not affected [79].

\subsection{Survival as a result of PKC $\delta$ sequestration out of the nucleus}

Nuclear accumulation of PKC $\delta$ induces death of self-reactive $B$ cells through ill-defined mechanisms that are nevertheless sufficient to prevent emergence of lupus-like autoimmune manifestations [80]. PKC $\delta$ was identified as a potential target for BAFF signaling, as $\mathrm{PKC} \delta$-deficient mice display an enlarged $B$ cell pool that shows reduced BAFF dependence for survival, and as BAFF signaling prevented nuclear accumulation of PKC $\delta$ [81]. Activation of the alternative NF- $\kappa \mathrm{B}$ pathway in response to BAFF was not impaired in $\mathrm{PKC}^{-1-}$ mice [81]. Consistent with this observation, B cells deficient in c-Myb that express lower levels of BAFF-R are not fully able to prevent nuclear accumulation of PKC $\delta$ following BAFF stimulation, leading to reduced $B$ cell survival [82]. The molecular link between BAFF-R and $\mathrm{PKC} \delta$ has not been investigated and a positive role of PKC $\delta$ downstream of TACI should not be excluded. 


\subsection{TACI and BAFF-R in the regulation of Ig switch}

In order for immunoglobulin class switch recombination to occur, at least two signals are required. One is provided by cytokines and the other is provided, in case of T-dependent antigens, by CD40. The importance of CD40 is highlighted in $\mathrm{CD} 40^{-1-}$ mice, which display severely reduced IgG1 and no IgE levels in their serum [83]. Nevertheless, IgA serum levels are only slightly altered, indicating that CD40-independent signals are important for class switch recombination to IgA. In human B cells, APRIL and BAFF induce class switch recombination independently of CD40, as measured at the nucleic acid level and by the upregulation of surface $\operatorname{IgG}$ and $\operatorname{IgA}$ [84]. Antibody secretion requires BCR stimulation [84]. The BAFF receptors mediating class switch recombination, namely BAFF-R and TACI, were identified using mice deficient in TACI, BCMA or BAFF-R [85]. BAFF-R can mediate class switch to IgG and IgE, and TACI to $\operatorname{IgG}, \operatorname{IgE}$ and $\operatorname{IgA}$. Class switch to IgE requires IL-4 $[85,86]$. Secretion of Ig in mice does not require BCR signaling as in human B cells, but relies on endogenously produced cytokines, such as IL-10.

Reduction in IgA serum levels was observed both in TACIdeficient mice [45] and in one out of two strains of APRILdeficient mice $[87,88]$. Consistently, BAFF Tg mice have enhanced IgA serum levels [89]. These data fit with a physiological role of TACI in IgA class switch recombination in the mouse. Recently patients affected with common variable immuno-deficiency (CVID) disorder have been identified with heterozygous or homozygous TACI mutations [90,91]. These patients have low levels of serum immunoglobulins, or selective IgA deficiency, but normal or increased B cell numbers [90,91]. Interestingly, the same mutation in the heterozygous state was shown to yield either severe CVID or no symptoms in a brother and a sister, highlighting the requirement for other genetic or environmental factors in the development of CVID [90].

TACI was originally identified for its ability to bind CAML (calcium-modulator and cyclophilin ligand) and subsequently activate the transcription factor NF-AT [5,11]. It is intriguing that a TACI mutation discovered in CVID patients (R202H) lies within the large and poorly defined CAML binding site. It is however not clear if this mutation would affect CAML signaling. $\mathrm{CAML}^{-1-}$ mice are not viable [92], and specific ablation of CAML in T cells impairs T cell development [93]. The role and relevance of NF-AT activation in B cells remains unknown.

Heterozygous mutations in BAFF-R have also been identified in CVID patients, although these mutations were also found in the control population, albeit at a lower frequency [94]. Thus, TACI and/or BAFF-R are likely mediators of CD40-independent class switch recombination, which occurs mainly during a $\mathrm{T}$ cell-independent response. As T cell-independent class switch occurs in splenic marginal zone or intestinal lamina propria B cells [95], it is not surprising that TACI expression was not or only weakly detected in germinal center B cells from human tonsils $[50,71]$.

The signaling pathway which accounts for induction of class switch recombination downstream of the BAFF and APRIL receptors is not well described. In human B cells, BAFF stimulation-induced class switch recombination in a p38- and JNK-dependent but Erk-independent manner [96]. Indeed, inhibition of these pathways using specific inhibitors leads to a reduction in class switch recombination. Involvement of NF$\mathrm{\kappa B}$ was not studied, nor was it determined which receptors were responsible for activating these signaling pathways.

\subsection{BAFF-R promotes expression of $C D 23$ and of the $B$ cell co-receptor complex, and BCMA favors antigen presentation}

The B cell co-receptor complex, consisting of CD19, CD21 and $\mathrm{CD} 81$, binds to complement $\mathrm{C} 3$. Opsonized antigens of blood-borne pathogens can cross-link the BCR to the B cell co-receptor, lowering the threshold of $\mathrm{B}$ cell activation and allowing rapid, T-independent antibody production. BAFF may enhance function of the $\mathrm{B}$ cell co-receptor complex, by allowing expression of CD21 [39], and upregulation and phosphorylation of CD19 [97]. Signaling through BAFF-R is required for normal CD21 and CD23 expression, although downregulation of the surface markers is less pronounced in BAFF- $\mathrm{R}^{-1-}$ mice than in $\mathrm{BAFF}^{-1-}$ mice, indicating that another receptor might be important [43]. Nevertheless, ablation of TACI and BCMA does not affect CD21 and CD23 expression [43]. Interestingly, CD23 downregulation is observed in BAFF ${ }^{-1-}$ and BAFF- $\mathrm{R}^{-1-}$ mice, but not in $\mathrm{A} / \mathrm{WySnJ}$ mice [43], which express a mutant BAFF-R, nor in TACI-Ig transgenic mice [76], suggesting that residual signaling through BAFF-R might be enough to fulfill this function. In the absence of TRAF2, CD21 is upregulated, consistent with TRAF2 being a negative regulator of BAFF-R signaling, whereas $\mathrm{CD} 23$ remains unaffected [61]. Upregulation of CD19 has been proposed to occur through induction of the B cell-specific transcription factor Pax5/BSAP [97]. However, regulation of the $\mathrm{B}$ cell co-receptor is not sufficient by itself to rationalize the effects of BAFF on T-independent type II antibody responses, as these responses are more severely impaired in $\mathrm{BAFF}^{-1-}$ and $\mathrm{TACI}^{-1-}$ than in $\mathrm{BAFFR}^{-1-}$ mice. B1 B cells might also be important contributors to T-I II responses. Consistent with this idea, TACI is expressed on $\mathrm{B} 1 \mathrm{~B}$ cells along with BAFF-R [43], and these cells are responsive to APRIL [98].

Signaling through BCMA was linked to enhanced antigen presentation [74]. In primary B cells, BCMA expression can be induced through IL-4 and -6 . On these stimulated B cells, BCMA signaling led to expression of several surface molecules known to be important for antigen presentation, in an NF-кBand JNK-dependent manner [74]. This effect of BCMA is probably irrelevant in plasma cells that do not present antigen. In the A20 B cell line, the authors detected JNK activation through BCMA only, in contrast with previous data, which showed that TACI could activate JNK in the same cell line [75].

\section{Concluding remarks}

The BAFF subfamily shows a fascinating complexity at the levels of protein expression, ligand receptor interactions, signaling and functional outcomes. The past few years have witnessed considerable progress in our molecular understanding of ligand 
receptor specificity, and on the function of individual receptors. Although key features of signaling events leading to B cell survival have been highlighted, we are still far away from a complete molecular understanding of these signaling events. Providing a clearer picture will be a challenge for studies in the coming years.

\section{Acknowledgments}

We thank Helen Everett for careful reading of the manuscript. This work was supported by grants from the Swiss National Science Foundation, including a grant from the NCCR (National Center of Competence in Research) Molecular Oncology.

\section{References}

[1] Hahne M, Kataoka T, Schroter M, Hofmann K, Irmler M, Bodmer JL, et al. APRIL, a new ligand of the tumor necrosis factor family, stimulates tumor cell growth. J Exp Med 1998;188:1185-90.

[2] Shu HB, Hu WH, Johnson H. TALL-1 is a novel member of the TNF family that is down-regulated by mitogens. J Leukocyte Biol 1999;65:680-3.

[3] Schneider P, MacKay F, Steiner V, Hofmann K, Bodmer JL, Holler N, et al. BAFF, a novel ligand of the tumor necrosis factor family, stimulates B cell growth. J Exp Med 1999;189:1747-56.

[4] Moore PA, Belvedere O, Orr A, Pieri K, LaFleur DW, Feng P, et al. BLyS: member of the tumor necrosis factor family and B lymphocyte stimulator. Science 1999;285:260-3.

[5] von Bulow GU, Bram RJ. NF-AT activation induced by a CAMLinteracting member of the tumor necrosis factor receptor superfamily. Science 1997;278:138-41.

[6] Thompson JS, Bixler SA, Qian F, Vora K, Scott ML, Cachero TG, et al. BAFF-R, a newly identified TNF receptor that specifically interacts with BAFF. Science 2001;293:2108-11.

[7] Yan M, Brady JR, Chan B, Lee WP, Hsu B, Harless S, et al. Identification of a novel receptor for B lymphocyte stimulator that is mutated in a mouse strain with severe B cell deficiency. Curr Biol 2001;11:1547-52.

[8] Laabi Y, Gras MP, Carbonnel F, Brouet JC, Berger R, Larsen CJ, et al. A new gene, BCM, on chromosome 16 is fused to the interleukin 2 gene by a $\mathrm{t}(4 ; 16)(\mathrm{q} 26 ; \mathrm{p} 13)$ translocation in a malignant $\mathrm{T}$ cell lymphoma. Embo J 1992;11:3897-904.

[9] Ingold K, Zumsteg A, Tardivel A, Huard B, Steiner QG, Cachero TG, et al. Identification of proteoglycans as the APRIL-specific binding partners. J Exp Med 2005;201:1375-83.

[10] Hendriks J, Planelles L, de Jong-Odding J, Hardenberg G, Pals ST, Hahne M, et al. Heparan sulfate proteoglycan binding promotes APRILinduced tumor cell proliferation. Cell Death Differ 2005;12:637-48.

[11] Bischof D, Elsawa SF, Mantchev G, Yoon J, Michels GE, Nilson A, et al. Selective activation of TACI by syndecan-2. Blood 2005 .

[12] Schneider P. The role of APRIL and BAFF in lymphocyte activation. Curr Opin Immunol 2005;17:282-9.

[13] Ng LG, Mackay CR, Mackay F. The BAFF/APRIL system: life beyond B lymphocytes. Mol Immunol 2005;42:763-72.

[14] Kalled SL, Ambrose C, Hsu YM. The biochemistry and biology of BAFF APRIL and their receptors. Curr Dir Autoimmun 2005;8:206-42.

[15] Liu Y, Xu L, Opalka N, Kappler J, Shu HB, Zhang G. Crystal structure of sTALL-1 reveals a virus-like assembly of TNF family ligands. Cell 2002;108:383-94.

[16] Zhukovsky EA, Lee JO, Villegas M, Chan C, Chu S, Mroske C. TNF ligands: is TALL-1 a trimer or a virus-like cluster? Nature 2004;427:413-4 (discussion 414).

[17] Cachero TG, Schwartz IM, Qian F, Day ES, Bossen C, Ingold K, et al. Formation of virus-like clusters is an intrinsic property of the tumor necrosis factor family member BAFF (B cell activating factor). Biochemistry $2006 ; 45: 2006-13$.
[18] Gavin AL, Ait-Azzouzene D, Ware CF, Nemazee D. DeltaBAFF, an alternate splice isoform that regulates receptor binding and biopresentation of the B cell survival cytokine BAFF. J Biol Chem 2003;278: 38220-8.

[19] Gavin AL, Duong B, Skog P, Ait-Azzouzene D, Greaves DR, Scott $\mathrm{ML}$, et al. deltaBAFF, a splice isoform of BAFF, opposes full-length BAFF activity in vivo in transgenic mouse models. J Immunol 2005;175: $319-28$.

[20] Vogt G, Chapgier A, Yang K, Chuzhanova N, Feinberg J, Fieschi C, et al. Gains of glycosylation comprise an unexpectedly large group of pathogenic mutations. Nat Genet 2005;37:692-700.

[21] Gras MP, Laabi Y, Linares-Cruz G, Blondel MO, Rigaut JP, Brouet JC, et al. BCMAp: an integral membrane protein in the Golgi apparatus of human mature B lymphocytes. Int Immunol 1995;7:1093-106.

[22] Kelly K, Manos E, Jensen G, Nadauld L, Jones DA. APRIL/TRDL-1, a tumor necrosis factor-like ligand, stimulates cell death. Cancer Res 2000;60:1021-7.

[23] Yan M, Wang LC, Hymowitz SG, Schilbach S, Lee J, Goddard A, et al. Two-amino acid molecular switch in an epithelial morphogen that regulates binding to two distinct receptors. Science 2000;290:523-7.

[24] Pradet-Balade B, Medema JP, Lopez-Fraga M, Lozano JC, Kolfschoten GM, Picard A, et al. An endogenous hybrid mRNA encodes TWEPRIL, a functional cell surface TWEAK-APRIL fusion protein. Embo J 2002;21:5711-20.

[25] Shu HB, Johnson H. B cell maturation protein is a receptor for the tumor necrosis factor family member TALL-1. Proc Natl Acad Sci USA 2000;97:9156-61.

[26] Hatzoglou A, Roussel J, Bourgeade MF, Rogier E, Madry C, Inoue J, et al. TNF receptor family member BCMA (B cell maturation) associates with TNF receptor-associated factor (TRAF) 1 TRAF2, and TRAF3 and activates NF-kappa B, elk-1, c-Jun N-terminal kinase, and p38 mitogenactivated protein kinase. J Immunol 2000;165:1322-30.

[27] Xu LG, Shu HB. TNFR-associated factor-3 is associated with BAFF-R and negatively regulates BAFF-R-mediated NF-kappa B activation and IL-10 production. J Immunol 2002;169:6883-9.

[28] Ni CZ, Oganesyan G, Welsh K, Zhu X, Reed JC, Satterthwait AC, et al. Key molecular contacts promote recognition of the BAFF receptor by TNF receptor-associated factor 3: implications for intracellular signaling regulation. J Immunol 2004;173:7394-400.

[29] Hymowitz SG, Patel DR, Wallweber HJ, Runyon S, Yan M, Yin J, et al. Structures of APRIL-receptor complexes: like BCMA, TACI employs only a single cysteine-rich domain for high affinity ligand binding. J Biol Chem 2005;280:7218-27.

[30] Dillon SR, Gross JA, Ansell SM, Novak AJ. An APRIL to remember: novel TNF ligands as therapeutic targets. Nat Rev Drug Discov 2006.

[31] Liu Y, Hong X, Kappler J, Jiang L, Zhang R, Xu L, et al. Ligandreceptor binding revealed by the TNF family member TALL-1. Nature 2003;423:49-56.

[32] Kim HM, Yu KS, Lee ME, Shin DR, Kim YS, Paik SG, et al. Crystal structure of the BAFF-BAFF-R complex and its implications for receptor activation. Nat Struct Biol 2003;10:342-8.

[33] Bodmer JL, Schneider P, Tschopp J. The molecular architecture of the TNF superfamily. Trends Biochem 2002;27:19-26.

[34] Gordon NC, Pan B, Hymowitz SG, Yin J, Kelley RF, Cochran AG, et al. BAFF/BLyS receptor 3 comprises a minimal TNF receptor-like module that encodes a highly focused ligand-binding site. Biochemistry 2003:42:5977-83.

[35] Patel DR, Wallweber HJ, Yin J, Shriver SK, Marsters SA, Gordon NC, et al. Engineering an APRIL-specific B cell maturation antigen. J Biol Chem 2004;279:16727-35.

[36] Reichlin A, Hu Y, Meffre E, Nagaoka H, Gong S, Kraus M, et al. B cell development is arrested at the immature B cell stage in mice carrying a mutation in the cytoplasmic domain of immunoglobulin beta. J Exp Med 2001;193:13-23

[37] Schiemann B, Gommerman JL, Vora K, Cachero TG, Shulga-Morskaya $\mathrm{S}$, Dobles $\mathrm{M}$, et al. An essential role for BAFF in the normal development of B cells through a BCMA-independent pathway. Science 2001;293:2111-4 
[38] Gross JA, Dillon SR, Mudri S, Johnston J, Littau A, Roque R, et al. TACI-Ig neutralizes molecules critical for B cell development and autoimmune disease. impaired B cell maturation in mice lacking BLyS. Immunity 2001;15:289-302.

[39] Gorelik L, Cutler AH, Thill G, Miklasz SD, Shea DE, Ambrose C, et al. Cutting edge: BAFF regulates $\mathrm{CD} 21 / 35$ and $\mathrm{CD} 23$ expression independent of its B cell survival function. J Immunol 2004;172:762-6.

[40] Tardivel A, Tinel A, Lens S, Steiner QG, Sauberli E, Wilson A, et al. The anti-apoptotic factor Bcl-2 can functionally substitute for the B cell survival but not for the marginal zone B cell differentiation activity of BAFF. Eur J Immunol 2004;34:509-18.

[41] Amanna IJ, Dingwall JP, Hayes CE. Enforced bcl-xL gene expression restored splenic B lymphocyte development in BAFF-R mutant mice. J Immunol 2003;170:4593-600.

[42] Sasaki Y, Casola S, Kutok JL, Rajewsky K, Schmidt-Supprian M. TNF family member B cell-activating factor (BAFF) receptor-dependent and -independent roles for BAFF in B cell physiology. J Immunol 2004;173:2245-52.

[43] Shulga-Morskaya S, Dobles M, Walsh ME, Ng LG, MacKay F, Rao SP, et al. B cell-activating factor belonging to the TNF family acts through separate receptors to support $\mathrm{B}$ cell survival and $\mathrm{T}$ cell-independent antibody formation. J Immunol 2004;173:2331-41.

[44] Yan M, Wang H, Chan B, Roose-Girma M, Erickson S, Baker T, et al. Activation and accumulation of B cells in TACI-deficient mice. Nat Immunol 2001;2:638-43.

[45] von Bulow GU, van Deursen JM, Bram RJ. Regulation of the Tindependent humoral response by TACI. Immunity 2001;14:573-82.

[46] Seshasayee D, Valdez P, Yan M, Dixit VM, Tumas D, Grewal IS. Loss of TACI causes fatal lymphoproliferation and autoimmunity, establishing TACI as an inhibitory BLyS receptor. Immunity 2003;18: $279-88$.

[47] Xu S, Lam KP. B-cell maturation protein, which binds the tumor necrosis factor family members BAFF and APRIL, is dispensable for humoral immune responses. Mol Cell Biol 2001;21:4067-74.

[48] O'Connor BP, Raman VS, Erickson LD, Cook WJ, Weaver LK, Ahonen $\mathrm{C}$, et al. BCMA is essential for the survival of long-lived bone marrow plasma cells. J Exp Med 2004;199:91-8.

[49] Avery DT, Kalled SL, Ellyard JI, Ambrose C, Bixler SA, Thien M, et al. BAFF selectively enhances the survival of plasmablasts generated from human memory B cells. J Clin Invest 2003;112:286-97.

[50] Zhang X, Park CS, Yoon SO, Li L, Hsu YM, Ambrose C, et al. BAFF supports human B cell differentiation in the lymphoid follicles through distinct receptors. Int Immunol 2005;17:779-88.

[51] Bonizzi G, Karin M. The two NF-kappaB activation pathways and their role in innate and adaptive immunity. Trends Immunol 2004;25:280-8.

[52] Aggarwal BB. Signalling pathways of the TNF superfamily: a doubleedged sword. Nat Rev Immunol 2003;3:745-56.

[53] Hauer J, Puschner S, Ramakrishnan P, Simon U, Bongers M, Federle $\mathrm{C}$, et al. TNF receptor (TNFR)-associated factor (TRAF) 3 serves as an inhibitor of TRAF2/5-mediated activation of the noncanonical NFkappaB pathway by TRAF-binding TNFRs. Proc Natl Acad Sci USA 2005;102:2874-9.

[54] Claudio E, Brown K, Park S, Wang H, Siebenlist U. BAFF-induced NEMO-independent processing of NF-kappa B2 in maturing B cells. Nat Immunol 2002;3:958-65.

[55] Kaisho T, Takeda K, Tsujimura T, Kawai T, Nomura F, Terada N, et al. IkappaB kinase alpha is essential for mature B cell development and function. J Exp Med 2001;193:417-26.

[56] Franzoso G, Carlson L, Xing L, Poljak L, Shores EW, Brown KD, et al. Requirement for NF-kappaB in osteoclast and B-cell development. Genes Dev 1997;11:3482-96.

[57] Hatada EN, Do RK, Orlofsky A, Liou HC, Prystowsky M, MacLennan IC, et al. NF-kappa B1 p50 is required for BLyS attenuation of apoptosis but dispensable for processing of NF-kappa B2 p100 to p52 in quiescent mature B cells. J Immunol 2003;171:761-8.

[58] Qian Y, Zhao Z, Jiang Z, Li X. Role of NF kappa B activator Act1 in CD40-mediated signaling in epithelial cells. Proc Natl Acad Sci USA 2002;99:9386-91.
[59] Xu Y, Cheng G, Baltimore D. Targeted disruption of TRAF3 leads to postnatal lethality and defective T-dependent immune responses. Immunity 1996;5:407-15.

[60] Liao G, Zhang M, Harhaj EW, Sun SC. Regulation of the NF-kappaBinducing kinase by tumor necrosis factor receptor-associated factor 3induced degradation. J Biol Chem 2004;279:26243-50.

[61] Grech AP, Amesbury M, Chan T, Gardam S, Basten A, Brink R. TRAF2 differentially regulates the canonical and noncanonical pathways of NFkappaB activation in mature B cells. Immunity 2004;21:629-42.

[62] Ramakrishnan P, Wang W, Wallach D. Receptor-specific signaling for both the alternative and the canonical NF-kappaB activation pathways by NF-kappaB-inducing kinase. Immunity 2004;21:477-89.

[63] Qian Y, Qin J, Cui G, Naramura M, Snow EC, Ware CF, et al. Act1, a negative regulator in CD40- and BAFF-mediated B cell survival. Immunity 2004;21:575-87.

[64] Chen C, Edelstein LC, Gelinas C. The Rel/NF-kappaB family directly activates expression of the apoptosis inhibitor Bcl-x(L). Mol Cell Biol 2000;20:2687-95.

[65] Viatour P, Bentires-Alj M, Chariot A, Deregowski V, de Leval L, Merville MP, et al. NF-kappa B2/p100 induces Bcl-2 expression. Leukemia 2003;17:1349-56.

[66] Grossmann M, O'Reilly LA, Gugasyan R, Strasser A, Adams JM, Gerondakis S. The anti-apoptotic activities of Rel and RelA required during B-cell maturation involve the regulation of $\mathrm{Bcl}-2$ expression. Embo J 2000;19:6351-60.

[67] Glasgow JN, Wood T, Perez-Polo JR. Identification and characterization of nuclear factor kappaB binding sites in the murine bcl-x promoter. $\mathrm{J}$ Neurochem 2000;75:1377-89.

[68] Trescol-Biemont MC, Verschelde C, Cottalorda A, Bonnefoy-Berard $\mathrm{N}$. Regulation of A1/Bfl-1 expression in peripheral splenic B cells. Biochimie 2004;86:287-94.

[69] Hsu BL, Harless SM, Lindsley RC, Hilbert DM, Cancro MP. Cutting edge: BLyS enables survival of transitional and mature B cells through distinct mediators. J Immunol 2002;168:5993-6.

[70] Huard B, Schneider P, Mauri D, Tschopp J, French LE. T cell costimulation by the TNF ligand BAFF. J Immunol 2001;167:6225-31.

[71] Ng LG, Sutherland AP, Newton R, Qian F, Cachero TG, Scott ML, et al. B cell-activating factor belonging to the TNF family (BAFF)-R is the principal BAFF receptor facilitating BAFF costimulation of circulating T and B cells. J Immunol 2004;173:807-17.

[72] Ye Q, Wang L, Wells AD, Tao R, Han R, Davidson A, et al. BAFF binding to $\mathrm{T}$ cell-expressed BAFF-R costimulates $\mathrm{T}$ cell proliferation and alloresponses. Eur J Immunol 2004;34:2750-9.

[73] Diaz-de-Durana Y, Mantchev GT, Bram RJ, Franco A. TACI-BLyS signaling via B-cell-dendritic cell cooperation is required for naive CD8 + T-cell priming in vivo. Blood 2006;107:594-601.

[74] Yang M, Hase H, Legarda-Addison D, Varughese L, Seed B, Ting AT. $\mathrm{B}$ cell maturation antigen, the receptor for a proliferation-inducing ligand and B cell-activating factor of the TNF family, induces antigen presentation in B cells. J Immunol 2005;175:2814-24.

[75] Xia XZ, Treanor J, Senaldi G, Khare SD, Boone T, Kelley M, et al. TACI is a TRAF-interacting receptor for TALL-1, a tumor necrosis factor family member involved in B cell regulation. J Exp Med 2000;192: $137-43$.

[76] Schneider P, Takatsuka H, Wilson A, Mackay F, Tardivel A, Lens S, et al. Maturation of marginal zone and follicular B cells requires B cell activating factor of the tumor necrosis factor family and is independent of B cell maturation antigen. J Exp Med 2001;194:1691-7.

[77] Bouillet P, Metcalf D, Huang DC, Tarlinton DM, Kay TW, Kontgen F, et al. Proapoptotic Bcl-2 relative Bim required for certain apoptotic responses, leukocyte homeostasis, and to preclude autoimmunity. Science 1999;286:1735-8

[78] Craxton A, Draves KE, Gruppi A, Clark EA. BAFF regulates B cell survival by downregulating the BH3-only family member Bim via the ERK pathway. J Exp Med 2005;202:1363-74.

[79] Takeuchi O, Fisher J, Suh H, Harada H, Malynn BA, Korsmeyer SJ. Essential role of BAX, BAK in B cell homeostasis and prevention of autoimmune disease. Proc Natl Acad Sci USA 2005;102:11272-7. 
[80] Mecklenbrauker I, Saijo K, Zheng NY, Leitges M, Tarakhovsky A. Protein kinase Cdelta controls self-antigen-induced B-cell tolerance. Nature 2002;416:860-5.

[81] Mecklenbrauker I, Kalled SL, Leitges M, Mackay F, Tarakhovsky A. Regulation of B-cell survival by BAFF-dependent PKCdelta-mediated nuclear signaling. Nature 2004;431:456-61.

[82] Thomas MD, Kremer CS, Ravichandran KS, Rajewsky K, Bender TP. $\mathrm{c}-\mathrm{Myb}$ is critical for B cell development and maintenance of follicular B cells. Immunity 2005;23:275-86.

[83] Castigli E, Alt FW, Davidson L, Bottaro A, Mizoguchi E, Bhan $\mathrm{AK}$, et al. CD40-deficient mice generated by recombination-activating gene-2-deficient blastocyst complementation. Proc Natl Acad Sci USA 1994;91:12135-9.

[84] Litinskiy MB, Nardelli B, Hilbert DM, He B, Schaffer A, Casali P, et al. DCs induce CD40-independent immunoglobulin class switching through BLyS and APRIL. Nat Immunol 2002;3:822-9.

[85] Castigli E, Wilson SA, Scott S, Dedeoglu F, Xu S, Lam KP, et al. TACI and BAFF-R mediate isotype switching in B cells. J Exp Med 2005;201:35-9.

[86] Messner B, Stutz AM, Albrecht B, Peiritsch S, Woisetschlager M. Cooperation of binding sites for STAT6 and NF kappa B/rel in the IL-4induced up-regulation of the human IgE germline promoter. J Immunol 1997;159:3330-7.

[87] Castigli E, Scott S, Dedeoglu F, Bryce P, Jabara H, Bhan AK, et al. Impaired IgA class switching in APRIL-deficient mice. Proc Natl Acad Sci USA 2004;101:3903-8.

[88] Varfolomeev E, Kischkel F, Martin F, Seshasayee D, Wang H, Lawrence $\mathrm{D}$, et al. APRIL-deficient mice have normal immune system development. Mol Cell Biol 2004;24:997-1006.

[89] Khare SD, Sarosi I, Xia XZ, McCabe S, Miner K, Solovyev I, et al. Severe B cell hyperplasia and autoimmune disease in TALL-1 transgenic mice. Proc Natl Acad Sci USA 2000;97:3370-5.
[90] Salzer U, Chapel HM, Webster AD, Pan-Hammarstrom Q, SchmittGraeff A, Schlesier M, et al. Mutations in TNFRSF13B encoding TACI are associated with common variable immunodeficiency in humans. Nat Genet 2005;37:820-8.

[91] Castigli E, Wilson SA, Garibyan L, Rachid R, Bonilla F, Schneider L, et al. TACI is mutant in common variable immunodeficiency and $\operatorname{IgA}$ deficiency. Nat Genet 2005;37:829-34.

[92] Tran DD, Russell HR, Sutor SL, van Deursen J, Bram RJ. CAML is required for efficient EGF receptor recycling. Dev Cell 2003;5:24556.

[93] Tran DD, Edgar CE, Heckman KL, Sutor SL, Huntoon CJ, van Deursen $\mathrm{J}$, et al. CAML is a p56Lck-interacting protein that is required for thymocyte development. Immunity 2005;23:139-52.

[94] Losi CG, Silini A, Fiorini C, Soresina A, Meini A, Ferrari S, et al. Mutational analysis of human BAFF receptor TNFRSF13C (BAFF-R) in patients with common variable immunodeficiency. J Clin Immunol 2005;25:496-502.

[95] Fagarasan S, Honjo T. T-Independent immune response: new aspects of B cell biology. Science 2000;290:89-92.

[96] Yamada T, Zhang K, Yamada A, Zhu D, Saxon A. B lymphocyte stimulator activates p38 mitogen-activated protein kinase in human Ig class switch recombination. Am J Respir Cell Mol Biol 2005;32:38894.

[97] Hase H, Kanno Y, Kojima M, Hasegawa K, Sakurai D, Kojima H, et al. $\mathrm{BAFF} / \mathrm{BLyS}$ can potentiate B-cell selection with the B-cell coreceptor complex. Blood 2004;103:2257-65.

[98] Planelles L, Carvalho-Pinto CE, Hardenberg G, Smaniotto S, Savino W, Gomez-Caro R, et al. APRIL promotes B-1 cell-associated neoplasm. Cancer Cell 2004;6:399-408.

[99] Day ES, Cachero TG, Qian F, Sun Y, Wen D, Pelletier M, et al. Selectivity of BAFF/BLyS and APRIL for binding to the TNF family receptors BAFFR/BR3 and BCMA. Biochemistry 2005;44:1919-31. 